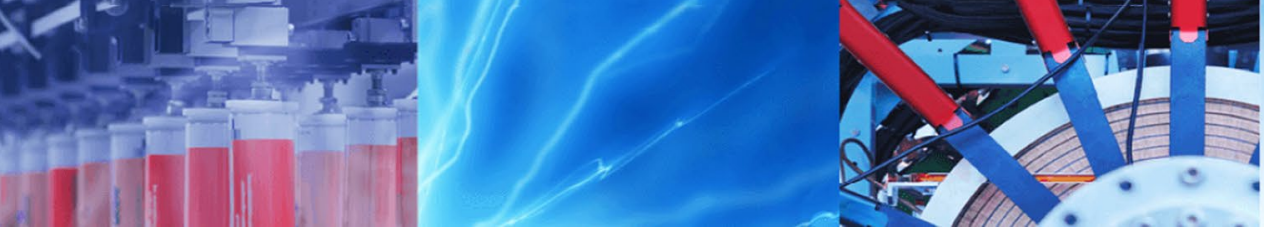

Research Article

\title{
Mapping and modeling within-tree variation for loblolly pine pulp yield and lignin content
}

\author{
Laurence R. Schimleck ${ }^{1}$ (1) - Finto Antony ${ }^{2} \cdot$ Christian Mora $^{3} \cdot$ Joseph Dahlen $^{2}$
}

Received: 29 September 2020 / Accepted: 25 February 2021 / Published online: 18 March 2021

(C) The Author(s) 2021 OPEN

\begin{abstract}
We examined the within-tree variation of pulp yield and lignin content for loblolly pine (Pinus taeda L.) trees aged 13 and 22 years. Radial trends in pulp yield (increase) and lignin (decrease) were consistent with what would be expected for loblolly pine as were changes in properties related to maturation. Maps, based on the average of 18 trees at each age, depicting pulp yield variation within-tree were similar to loblolly pine maps reported for microfibril angle and stiffness, while lignin maps resembled the inverse of those reported for density and related properties. Mixed-effects models for both properties were developed with the base model for pulp yield explaining $64 \%$ of the observed variation, with the inclusion of tree height improving the model slightly, whereas models for lignin content explained $44 \%$ of the variability. The models could be incorporated into growth and yield prediction systems, or procurement model systems that predict within-tree wood properties based on age and tree size.
\end{abstract}

Keywords Lignin content · Loblolly pine · Near-infrared spectroscopy · Nonlinear wood property models · Pinus taeda . Pulp yield $\cdot$ Wood property maps

\section{Introduction}

Loblolly pine (Pinus taeda L.), native to the southeastern USA, is one of the most important plantation species in world. It is heavily utilized by the pulp industry in the US south, historically a major producer of Kraft pulp [27], and in $2016,78 \%$ of total pulpwood production in the region was from conifer roundwood and residues [20]. Loblolly pine is used to produce a range of pulps (Kraft is the most common) and to manufacture a variety of products $[26,47$, 58]. The revenue generated by the pulp and paper sector is significant; for example, in Georgia this sector generates $65 \%$ of the total forestry and forest products revenue [18]. Despite the importance of loblolly pine for Kraft pulp production, limited information exists for this species (and hardwood and softwood species in general) regarding within-tree variation of pulp yield and lignin content, two properties directly related to the economics of pulp production [21, 64].

The lack of information on within-tree variability relates directly to the high cost associated with determining many of the properties considered important for pulp manufacture, particularly pulp yield, and to a lesser degree lignin content, which both require detailed wet chemistry methods for determination. Koch [27] reports that for a Kappa number of 109 southern pine pulp yield will be approximately $57 \%$, whereas the typical lignin range for southern pine pulpwood is from 26 to $29 \%$. More recently, Kim et al. [26] reported screened Kraft pulp yields of $44.6 \%$ (Kappa number $=27.4)$ for loblolly pine thinnings and $45.6 \%$ (Kappa number $=24.2$ ) for mature wood, whereas lignin

$\triangle$ Laurence R. Schimleck, laurence.schimleck@oregonstate.edu; Finto Antony, fintoa@gmail.com; Christian Mora, crmora@fibraconsult.cl; Joseph Dahlen, jdahlen@uga.edu | ${ }^{1}$ Department of Wood Science and Engineering, College of Forestry, Oregon State University, Corvallis, OR 97331, USA. ${ }^{2}$ Warnell School of Forestry and Natural Resources, University of Georgia, 180 E. Green Street, Athens, GA 30602, USA. ${ }^{3} 4030000$ Fibraconsult, Concepcion, Chile 
contents varied from $29.8 \%$ (thinnings) to $28.5 \%$ (mature wood).

In conifers, it is recognized that corewood (or juvenile wood) has lower cellulose (included here as an indicator of pulp yield) and higher lignin content compared to outerwood (or mature wood) $[45,63]$. Specifically, a radial trend of increasing pulp yield for Norway spruce (Picea abies (L.) Karst.) was observed by Molteberg and Høibø [40], which is consistent with the radial increases in a-cellulose and glucan (especially for the first 10-15 growth rings after which it increased slowly), and decreasing trends of pentosans and lignin observed by Harwood [22] and Uprichard [62] in radiata pine (Pinus radiata D. Don). Various authors have reported a decrease in lignin, including Larson [29] for red pine (Pinus resinosa Sol. ex Aiton), Ericksen and Arima [13] for Douglas fir (Pseudotsuga menziesii (Mirb.) Franco) and Via et al. [63] for longleaf pine (Pinus palustris Mill.). In comparison, Gierlinger and Wimmer [19] reported increasing radial trends for lignin in European larch (Larix decidua Mill.) from sites in Austria and France; however, the trees were much older than those examined by the other authors (146 and 250 years old, respectively). More recently, near-infrared hyperspectral imaging (NIR-HSI) has been utilized $[37,59,60]$ to examine within-tree variation for various wood sugars and lignin content in radiata pine. Meder et al. [37] reported radial trends of increasing glucose and decreasing lignin for spectra from increment cores, while Thumm et al. [59] mapped wood property variation for a radiata pine disk, finding elevated levels of galactose and lignin, and lower glucose in a region with pronounced compression wood.

Studies of within-tree variation of pulp yield in eucalypts are more common. Batchelor et al. [3, 4] in Australia and Manfredi [35] in Brazil reported yield variation with height, with the earliest maps of yield variation withintrees reported by Crawford et al. [7] for two large Tasmanian grown alpine ash (Eucalyptus delegatensis R. T. Baker) trees (large trees were required to provide sufficient sample for pulping). Schimleck and Michell [53] developed maps illustrating pulp yield variability within plantationgrown shining gum (Eucalyptus nitens (H. Deane \& Maiden) Maiden) based on NIR spectroscopic estimates of pulp yield for individual ring samples. In recent studies, Downes et al. [11, 12] have utilized NIR spectroscopy to examine pulp yield variation at high spatial resolution (1-mm increments) for shining gum and blue gum (Eucalyptus globulus (Labill.)).

In addition to chemical changes, pulp product properties are influenced by fiber (tracheid) property changes that occur within-trees. For properties such as tracheid length and width, which can be determined at a relatively low cost compared to pulp yield, some maps are available. Examples include Lundqvist et al. [31] and Dahlen et al.
[9] for loblolly pine, Mäkinen et al. [34] for Norway spruce, while lkonen et al. [23] developed maps for tracheid length only for Scots pine (Pinus sylvestris L.). In general, available literature is limited to plots of radial variation (sometimes at multiple heights) and the number of trees, by necessity, is limited [44]. The development of SilviScan [14] facilitated rapid measurement of tracheid dimensions and, coupled with density estimates, allowed the derivation of several additional properties including coarseness and wall thickness. Maps showing how these properties varied within radiata pine trees were reported by Evans et al. [17], while Defo et al. [10] utilized SilviScan data to develop coarseness maps for Douglas fir.

Recently, we have utilized NIR spectroscopy, calibrated with SilviScan reference data $[14,15,16]$, to map wood property variation in loblolly pine $[42,54]$ at different ages $[55,57]$. The wood property models used SilviScan data and NIR spectra collected in 10-mm increments from selected sections of a subsample of radial strips from multiple trees and at specific heights. NIR-based wood property models predicted properties in 10-mm increments for all strips at all heights, and with these data, whole-tree maps were developed (for these studies the maps represented the average of 18 trees at age 13 and another 18 trees at age 22). Presently, maps based on this approach have been reported for air-dry density, microfibril angle (MFA) and stiffness (MOE) and for a range of tracheidrelated properties such as coarseness, radial and tangential diameter, specific surface and wall thickness. Using a similar approach, but with a far larger data set (NIR spectra were collected from 11,428 10-mm sections), Dahlen et al. [9] developed maps demonstrating within-tree variation of tracheid length and width for loblolly pine samples from across the southeastern USA.

Most of these studies of within-tree variation involved using a "spatial-specific" model [56] as wood property data and the corresponding spectral data are measured from pith-to-bark and at multiple heights at the same spatial resolution (e.g., 10-mm radial increments). An alternative approach is to use a "spatial-interpolated" model [56] which involves "measuring a property at a broad scale, e.g., whole-tree, calibrating this data against NIR spectra representing the equivalent scale and then using the calibration to predict the property at higher resolution." Recently, Schimleck et al. [56] used both approaches to examine within-tree variation of density and coarseness and found that patterns of variation for maps obtained using the two approaches were comparable. Density was measured using SilviScan (= spatial-specific model data) and on chips produced from bolts (= spatial-interpolated model data). Similarly, tracheid coarseness was measured using SilviScan (spatial-specific) and on the pulp produced from the chips (spatial-interpolated). Coarseness values 
were adjusted to facilitate these comparisons as SilviScan measurements represented a "dry" coarseness measurement on non-pulped samples (i.e., cell wall thickness unaltered), while measurements on whole-tree measurements were on pulp samples suspended in water (cell wall thickness reduced/collapsed during pulping) $[6,25,52]$. Validation of the spatial-interpolated model approach is important as it gives confidence when using NIR models, developed for properties measured on whole-tree samples (e.g., pulp yield), to predict properties at a much higher resolution, e.g., 10-mm sections of a radial strip. It is important to note that the critical step in utilizing this approach is that NIR spectra collected in 10-mm increments at various radial positions and heights are area weighted to provide a representative whole-tree average spectrum for each tree. An assumption is that the spectra adequately represent the original whole-tree composite samples used for wood property analysis but small discrepancies owing to the different approaches used to obtain the two sets of whole-tree spectra are to be expected.

For the loblolly pine trees examined in Mora and Schimleck [42], Schimleck et al. [54, 55, 57] wood properties such as pulp yield, and lignin content were measured on whole-tree samples and provide an opportunity to utilize the spatial-interpolated model approach to investigate the within-tree variation of these properties. Hence, the goals of this study are:

a. To develop NIR-based whole-tree models for pulp yield, and lignin content utilizing the NIR dataset previously described;

b. Use the models to predict each wood property in 10-mm increments (spatial-interpolated approach); and

c. Model and examine the patterns of within-tree (radial and longitudinal) variation in pulp yield and lignin content.

\section{Material and methods}

\subsection{Sample origin}

Two sets of eighteen loblolly pine trees aged 13 and 22 years, respectively, were sampled from a half-sib progeny trial planted at International Paper's (IP) Southlands facility located in the lower coastal plain near Bainbridge, $\mathrm{GA}$. The trees were selected to encompass the range of cellulose, lignin and specific gravity variation within the larger populations as measured by IP. Average diameter at breast height for selected trees was $82.6 \mathrm{~mm}$ (age 13) and $96.1 \mathrm{~mm}$ (age 22), respectively. The trees were felled and samples removed for wood property and NIR analyses.
Disks (25-mm thick) were taken at 1.5-m intervals along the stem of each tree, giving 9 to 13 disks per tree (number depended on tree height). A total of 411 disks were used for the study: 191 disks collected from trees aged 13 years and 220 from the 22-year-old trees. In addition, the stems of each sampled tree were divided into four sections of equal length and a $0.75-\mathrm{m}$ bolt was cut from the center of each section.

\subsection{Pulp property measurements}

The four $0.75-\mathrm{m}$ bolts collected for each tree were chipped using a 1.2-m Carthage chipper at the Institute of Paper Science and Technology (IPST), Atlanta, GA, and then thoroughly mixed to give a single composite sample per tree. Several properties were measured on each composite sample; however, for this study we will only focus on pulp yield and lignin content. White et al. [64] provide a detailed description of the Kraft pulping process. Briefly, for each whole-tree composite sample duplicate cooks were performed on $1 \mathrm{~kg}$ of oven-dried whole-tree chips in a 10L M/K digester. Two pulp grades (linerboard at 100 Kappa and bleachable at $30 \mathrm{Kappa}$ ) were obtained for each sample, and Klason lignin content was determined according to the TAPPI T222-om-88 standard [64].

\subsection{Near-infrared spectroscopy}

\subsubsection{Sample preparation: radial strips}

Pith-to-bark radial sections were cut from each disk using a bandsaw. Section dimensions were $12.5 \mathrm{~mm}$ longitudinally by $12.5 \mathrm{~mm}$ tangentially with the radial length corresponding to the radius of the disk. Radial sections were dried in a $50{ }^{\circ} \mathrm{C}$ oven for $24 \mathrm{~h}$ and then air-dried, glued into core holders and cut using a twin-blade saw to give strips 2-mm-thick (tangentially) using the methodology described in Jordan et al. [24].

\subsubsection{Collection of NIR spectra}

All strips were conditioned and tested in a controlled environment room ( $40 \%$ relative humidity, $20^{\circ} \mathrm{C}$ ). NIR spectra were collected in 10-mm increments from the radial-longitudinal face of each radial strip using a FOSS NIRSystems Inc Model 5000 scanning spectrometer fitted with a 5 by $10 \mathrm{~mm}$ Teflon mask (to ensure spectra were collected from an area of consistent size). NIR spectra (an average of 50 scans for each $10 \mathrm{~mm}$ section) were collected over the wavelength range $1100-2498 \mathrm{~nm}$ in 2-nm increments. The total number of spectra collected was $2,569(1,114$ from 13-year-old trees and 1,455 from trees aged 22 years). Schimleck et al. [54] provide a more detailed description of 
the methodology used to collect NIR spectra. The annual rings were counted for each 10-mm interval to determine the mean cambial age for each $10-\mathrm{mm}$ section, which was used for the modeling efforts.

\subsection{Data analysis}

The data analysis and figures were produced in the R statistical programing environment [49] with the RStudio interface [50]. Data wrangling was done using the tidyverse series of packages [66]. NIR partial least squares (PLS) regression models were developed using the pls package [39]. Tree maps were produced using the akima [1], fields [43], and lattice [51] packages, while the other data visualizations were produced using ggplot2 [65]. Nonlinear mixed-effects models were developed using the nlme library [46]; those were compared using fit indices $\left(R^{2}\right)$ of the fixed, and fixed plus random (stand, tree) components of the models, and root mean square error (RMSE) values. All models were developed iteratively, keeping only those parameters with $p$-values less than or equal to 0.05 in the models.

\subsubsection{Determination of weighted whole-tree spectra}

Our NIR-based models for pulp yield and lignin content were developed at the whole-tree level (i.e. "spatial-interpolated"). The approach is described in Schimleck et al. [56] whereby the objective is to take the individual $10-\mathrm{mm}$ radial spectra (2,569 in total) and weight them by their basal area in order to obtain one spectrum that represents the individual tree (36 in total). The representative spectra for each tree are then used to developed calibration models for the properties measured at the whole tree level.

\subsubsection{Lignin and pulp yield calibrations}

Lignin and pulp yield PLS regression calibrations with leave-one-out cross-validation were developed. Calibration performance was assessed using the following parameters:

- Coefficient of determination $\left(R^{2}\right)$, the proportion of variation in the calibration set that was explained by the calibration;

- Coefficient of determination of cross-validation $\left(R_{\mathrm{cv}}{ }^{2}\right)$, the proportion of variation in the cross-validation set that was explained by the calibration;

- Standard error of calibration (SEC) determined from the residuals of the final calibration;

- Standard error of cross-validation (SECV) determined from the residuals of each cross-validation phase;
- Ratio of performance to deviation (RPD $)$ [67], calculated as the ratio of the standard deviation of the reference data to the SECV.

Determination of RPD allows comparison of calibrations for different properties that have differing data ranges and units, the higher the RPD, the more accurate the data are described by the calibration. The PLS models were then used to predict pulp yield and lignin for all 2,569 spectra in 10-mm increments.

\subsubsection{Maps of wood property variation within trees}

Mora and Schimleck [42] provide a detailed description of the methodologies they used to develop maps of withintree variation for air-dry density, MFA and MOE. Briefly, three different methods were explored: Akima's interpolation, universal kriging and semiparametric smoothing. Mora and Schimleck [42] reported that for loblolly pine, maps generated by Akima's interpolation method provided good representation of the expected trends in airdry density and MFA. In addition, they concluded that the principal advantage of Akima's algorithm over universal kriging and semiparametric smoothing techniques was that only straightforward procedures were required, and there were no problems concerning computational stability or convergence. Owing to these features, only Akima's interpolation method was used in this work.

\subsubsection{Estimation of whole-tree averages}

Following the Akima's interpolation method, mean pulp properties for each age were calculated by weighting the volume of each radial point compared to the overall volume and then summing each respective height. To do this, the basal area for each 10-mm radial section within a disk was calculated using:

area $_{\text {disk }}=\pi r_{o}^{2}-\pi r_{i}^{2}$

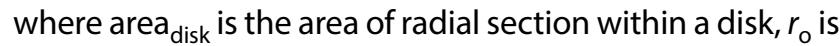
the outside radius, and $r_{i}$ is the inside radius. The weighted average property (pulp yield or lignin content) within a disk was calculated using:

property $_{\text {disk }}=\sum_{i=1}^{n} \frac{\text { area }_{i} \times \text { property }_{i}}{\text { area }_{\text {disk }}}$

where property $_{\text {disk }}$ is the weighted average property for a specific disk, area ${ }_{i}$ is the area that a specific $10-\mathrm{mm}$ radial section represents within a disk, property ${ }_{i}$ is the property at a specific $10-\mathrm{mm}$ radial section, area disk is the total area of a disk, and $n$ is the number of $10-\mathrm{mm}$ radial sections 
within each disk. The weighted average property was then calculated using:

property $_{\text {tree }}=\sum_{i=1}^{k} \frac{\text { area }_{\text {disk } \_i_{i}} \times \text { property }_{\text {disk_ } i}}{\text { area }_{\text {tree }}}$

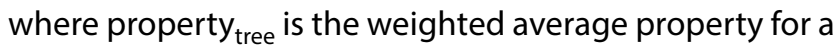
specific tree, area disk $i_{i}$ is the area that a specific disk represents, property disk $\__{i}$ is the calculated property for each disk, area $_{\text {tree }}$ is the total area for each tree, and $k$ is the number of disks within each tree. Note that the weighted average properties at lower height levels within each tree (such as the stump) represent a greater amount of the total area of the disks than the property at the tip of the tree. The calculated values were compared to measured values reported in White et al. [64].

\subsubsection{Within-tree pulp yield and lignin content model development}

Models for predicting pulp yield and lignin content as a function of cambial age (ring number) and height within tree were fitted. The within-tree variability of wood and fiber properties of plantation softwood species tend to vary based on these two variables (cambial age and height) more so than other variables such as the size of trees $[2,5,28]$. The model forms were selected by visual examination of the data. General radial trends found were an increase in pulp yield from pith to bark, and a consistent increase in pulp yield with height for a given ring for both corewood and outerwood. Lignin showed opposite radial trends, with a decrease in lignin content from pith to bark, and, for a given ring in the corewood, lignin content was lower with increasing tree height. Differences in lignin content based on height within tree for outerwood were not detected. For both models the effect of disk height was not linear. We took the natural logarithm of disk height (in meters) and added $1 \mathrm{~m}$ to each disk height value to prevent negative infinity values, and to reduce the slope of the natural log effect that occurs with values below $1[9,41]$.

For pulp yield, a three-parameter logistic function [48] was selected. This model form has been successfully used to model latewood specific gravity in loblolly pine [8] and tracheid width measured on macerated samples of loblolly pine [9]:

pulp $=\frac{\beta_{0}}{1+e^{\left(\frac{\beta_{1}-C A}{\beta_{2}}\right)}}$

where pulp is the mean ring pulp yield content (\%), CA is the cambial age (ring number), $\beta 0$ is the asymptote as cambial age approaches $+\infty, \beta 1$ the inflection point, and $\beta 2$ a scale parameter. In order to vary pulp yield by disk height in both corewood and outerwood, we incorporated disk height into the model:

pulp $=\frac{\beta_{0}}{1+e^{\left(\frac{\beta_{1}-C A}{\beta_{2}}\right)}}+\beta_{3} \log (\mathrm{DH}+1)$

where $\beta 3$ is the fixed effect parameter, and $\mathrm{DH}$ is the disk height. Considering random effects, $\beta 0$ was allowed to vary by site and tree:

pulp $=\frac{\beta_{0}+a_{i}+a_{i j}}{1+e^{\left(\frac{\beta_{1}-C A}{\beta_{2}}\right)}}+\beta_{3} \log (\mathrm{DH}+1)$

where $a_{i}$ and $a_{i j}$ represent the nested random effects of the asymptote parameter $\beta 0$ at the site $i$ and tree $j$ levels, respectively.

For lignin content, a variation on the three-parameter logistic function [48] was used which has previously been used to model earlywood specific gravity in loblolly pine [8]:

lignin $=\beta_{0} \times e^{\left(\frac{\beta_{1}}{C A+\beta_{2}}\right)}$

where lignin is the mean ring lignin content (\%), CA is the cambial age (ring number), $\beta 0$ is the asymptote reached when cambial age approaches $+\infty, \beta 1$ and $\beta 2$ both control the lignin content at the pith and the rate of change from pith to bark. In order to vary lignin content at the pith by disk height, we incorporated disk height into the dominator:

lignin $=\beta_{0} \times e^{\left(\frac{\beta_{1}}{\left(\mathrm{CA}+\beta_{2}+\beta_{3} \log (\mathrm{DH}+1)\right)}\right)}$

where $\beta_{3}$ is the fixed effect parameter and $\mathrm{DH}$ is the disk height. Considering random effects, $\beta_{0}$ was allowed to vary by site and tree:

lignin $=\left(\beta_{0}+a_{i}+a_{i j}\right) \times e^{\left(\frac{\beta_{1}}{\left(C \mathrm{~A}+\beta_{2}+\beta_{3} \log (\mathrm{DH}+1)\right)}\right)}$

where $a_{i}$ and $a_{i j}$ represent the nested random effects of the asymptote parameter $\left(\beta_{0}\right)$ at the site $i$ and tree $j$ levels, respectively.

\section{Results and discussion}

\subsection{Spatial-interpolated whole-tree lignin and pulp yield calibrations}

Spatial-interpolated NIR-based models for pulp yield and lignin were developed using data obtained for these 
properties on a whole-tree basis and basal area weighted 10-mm spectral data from each tree averaged to give a single representative spectrum per tree. Models are reported in Table 1 and plotted in Fig. 1, with the pulp yield ( 6 factors, $\left.R^{2}=0.72, R_{\mathrm{cv}}{ }^{2}=0.53, \mathrm{SECV}=1.10 \%\right)$ and lignin models ( 7 factors, $R^{2}=0.82, R_{\mathrm{cv}}{ }^{2}=0.51, \mathrm{SECV}=0.76 \%$ ) being comparable. The number of factors recommended for both models corresponded to a clear minimum in explained variance and $R_{\mathrm{cv}}{ }^{2}$ values continued to improve as the number of factors increased indicating that the models were not over-fitted. The pulp yield model compares well with that reported by White et al. [64] that was based on the same dataset but used NIR spectra collected from a representative chip sample processed from the whole-tree samples (intact chips were analyzed by NIR when green, after drying and after milling).

\subsection{Lignin and pulp yield maps}

Figures 2 and 3 show pulp yield and lignin maps that represent the average of 18 loblolly pine trees at ages 13 and 22, respectively, with age-related trends of increasing pulp yield, and decreasing lignin apparent. At both ages, the highest pulp yields (and lowest lignin contents) are observed at the periphery of the trees with the region of highest yield at a height of $4.5 \mathrm{~m}$. The range in within-tree property values is similar (approximately 7\%) for the 22-year-old maps, but the differences in the lignin content map appear more subtle as much of the variability is concentrated near the pith. Examination of the probability density plots (Fig. 4) of lignin content for the 22-year-old tree map shows that the majority of values fall in the range of $30-30.5 \%$ with very few lignin values less than $30 \%$.

The map for pulp yield (Fig. 2) is very similar to the loblolly pine maps reported for MFA, stiffness and tracheid length $[9,40,53]$, with trends present in both the radial and longitudinal directions. While the maps were reported for shining gum, the variation observed by Schimleck and Michell [53] was also similar to the pulp yield maps reported for loblolly pine.

The maps for lignin (Fig. 3) initially appear dissimilar to other maps showing within-tree variation in conifers. Closer inspection indicates that the variation, particularly for the 13-year-old lignin map, is similar to what has been reported for density in loblolly pine $[42,55]$ and radiata pine $[17,61]$ with lignin content decreasing radially as opposed to increasing radially as with density. In their summary of density variation in radiata pine and loblolly pine, Burdon et al. [5] note that this pattern of variation is typical of properties that demonstrate a radial increase (or decrease as observed for lignin) at all heights.
Table 1 Summary of the multiple height loblolly pine wood property calibrations developed for each wood property using all $36 \mathrm{NIR}$ spectra

\begin{tabular}{lllllll}
\hline Wood & \multicolumn{7}{l}{ Calibration set (36 spectra) } \\
\cline { 2 - 7 } Property & \# factors & $\mathrm{R}^{2}$ & $\mathrm{R}_{\mathrm{cv}}{ }^{2}$ & $\mathrm{SEC}$ & $\mathrm{SECV}$ & $\mathrm{RPD}_{\mathrm{c}}$ \\
\hline Pulp yield (\%) & 6 & 0.72 & 0.53 & 0.80 & 1.10 & 1.9 \\
Lignin content (\%) & 7 & 0.82 & 0.51 & 0.46 & 0.76 & 2.4 \\
\hline
\end{tabular}
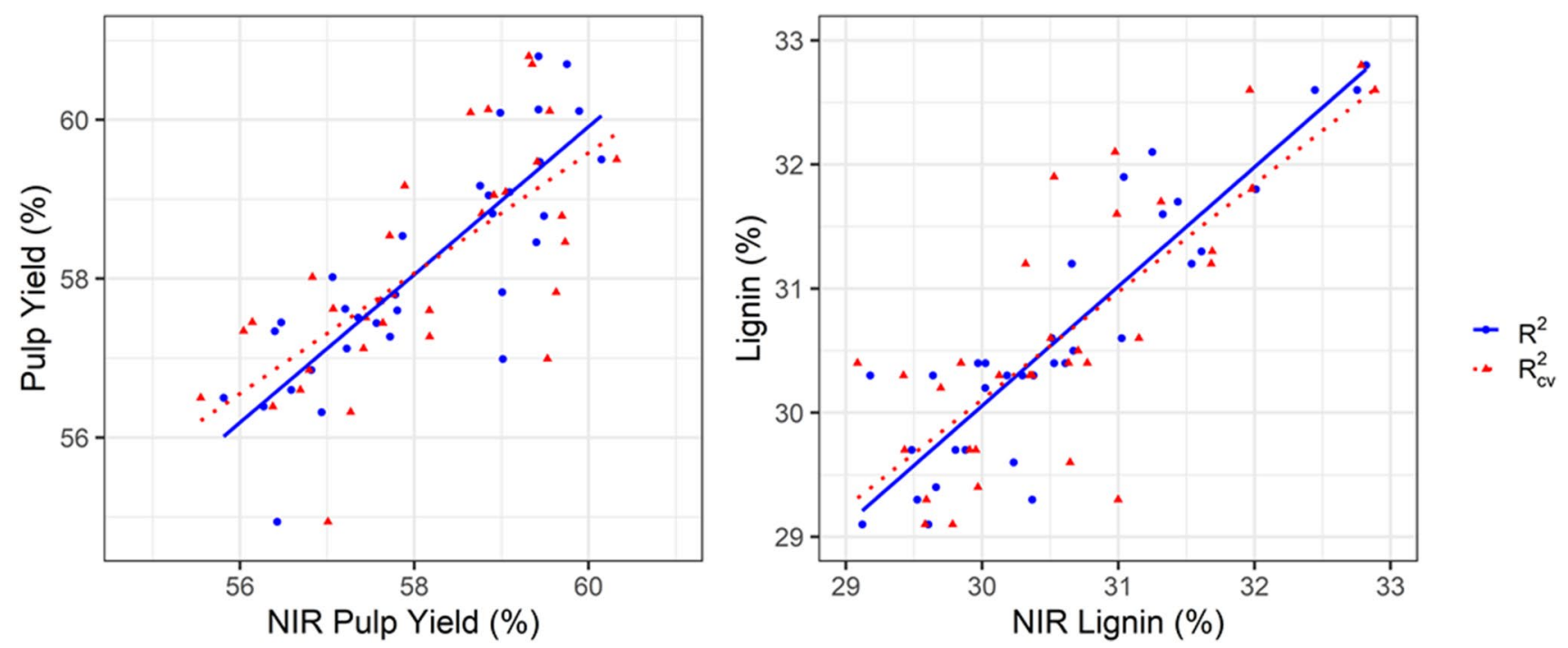

Fig. 1 Calibration plots for pulp yield and lignin content 


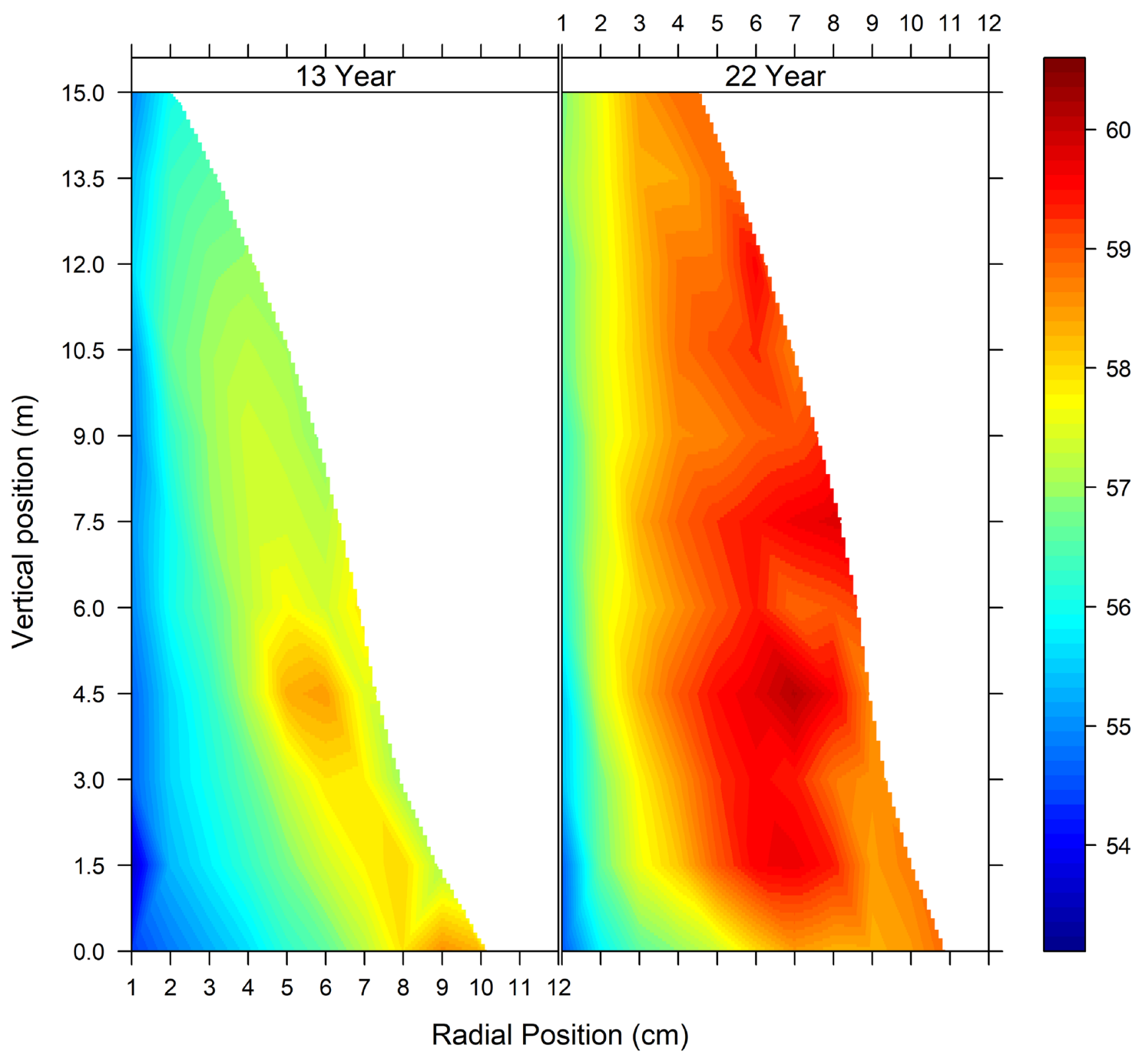

Fig. 2 Maps showing within-tree variation of pulp yield (\%) for loblolly pine trees aged 13 and 22 years. Maps at each age represent the average of 18 trees and were developed using Akima's interpolation method

In their study of Norway spruce, Molteberg and Høibø [40] observed that trees with larger diameter had a reduction in pulp yield. They related this observation to the wider rings of larger diameter trees having more earlywood, which owing to thinner cell walls and a reduction in the low lignin S2 layer of the cell wall, results in a relative increase in the amount of lignin. Similarly, an increase in density with age can be related to a decrease in lignin content (and an increase in cellulose content). Density in loblolly pine increases as the proportion of latewood [30, 24] increases and as corewood transitions to outerwood $[5,45]$. Latewood cells have a thick S2 layer that is relatively low in lignin and high in cellulose; hence, an increase in latewood percent (and density) should correspond to an overall reduction in lignin content. Burdon et al. [5] note the presence of such trends in radiata pine.

\subsection{Whole-tree averages}

Pulp yield and lignin averaged on a whole-tree basis were determined for individual trees at age 13 and 22-years. Pulp yield increased with an increase in age, whereas lignin decreased. The change in average tree values for both properties with age was relatively small with pulp 


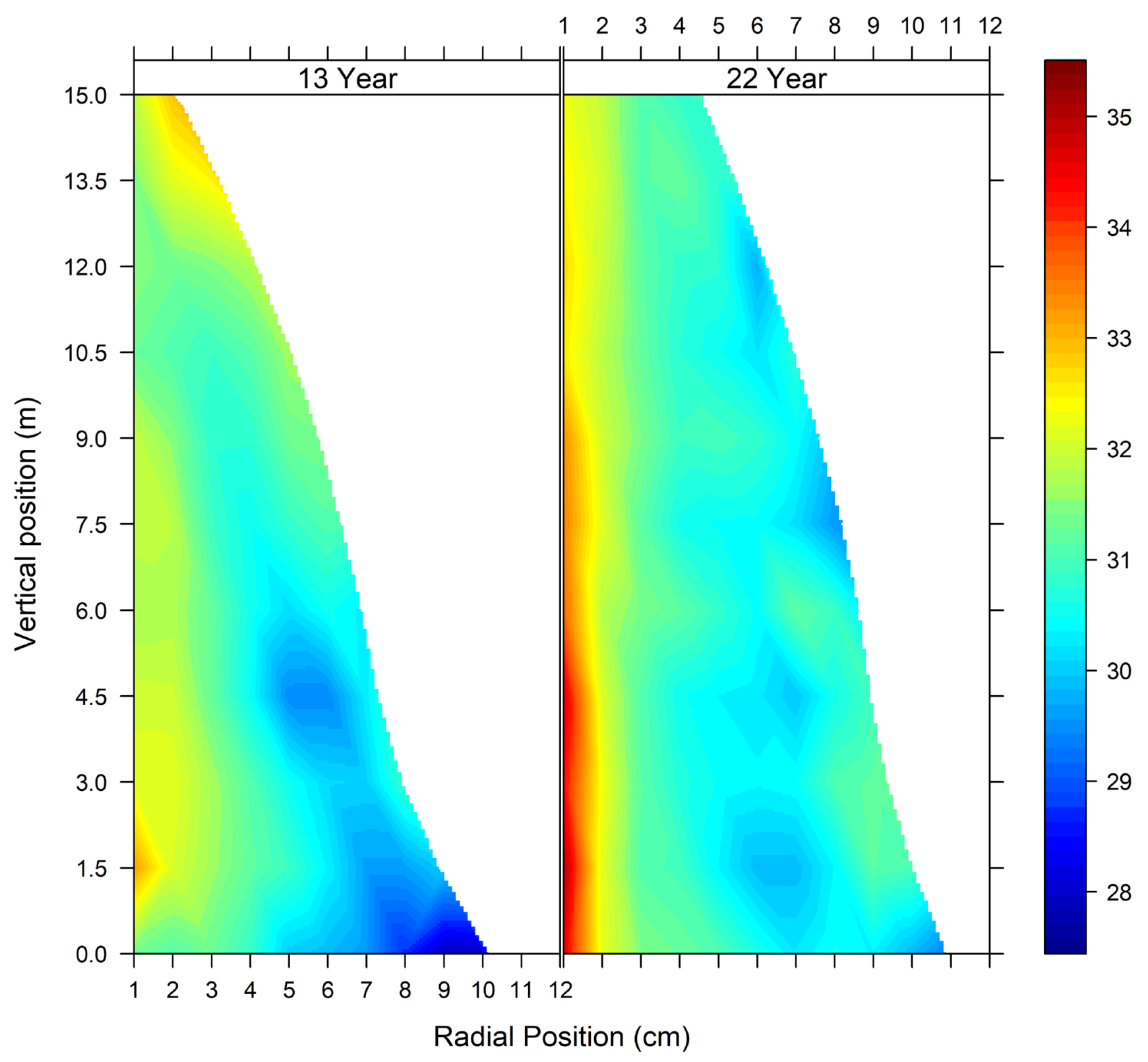

Fig. 3 Maps showing within-tree variation of lignin content (\%) for loblolly pine trees aged 13 and 22 years. Maps at each age represent the average of 18 trees and were developed using Akima's interpolation method

yield increasing from 57\% (13 years old) to 58.7\% (22 years old), and lignin content decreasing from $30.8 \%$ at 13 years to $30.6 \%$ at 22 . These values are comparable to those reported by McDonough et al. [36] who reported averages for pulp yield of $56.8 \%$ at age 13 and $59.4 \%$ (average Kappa number was 112) at 22 years and $30.4 \%$ and $30.6 \%$ for lignin content at 13 and 22 years, respectively.

Probability density plots (Fig. 4) show the distribution of pulp yield and lignin content for individual trees at ages 13 and 22 and age-related shifts in property means. As noted in [57], the 22-year-old trees have considerably more volume (approximately 50\%) than the 13-year-old trees.

\subsection{Models}

Plots showing variation in loblolly pine pulp yield and lignin content by cambial age and with height $(0.15$, 5.2 and $10.4 \mathrm{~m}$ ) within tree are shown in Figs. 5 and 6, respectively.

The pulp yield model (see Table 2 for parameter estimates) closely followed the tree map, whereby pulp yield increased radially, and pulp yield increased with height for a given cambial age. The increase was consistent throughout both the corewood and the outerwood, and the pulp yield change could be detected with height. Lignin 
Fig. 4 Probability (density) plots showing the variation of the predicted chemical properties for pulp yield and lignin content. The area under the density curves has a probability of one

Fig. 5 Variation in loblolly pine pulp yield by cambial age and height within tree. Lines represent the predictions from Eq. 3 at the following disk heights: $0.15 \mathrm{~m}$ (solid), $5.2 \mathrm{~m}$ (dotted), $10.4 \mathrm{~m}$ (dashed)
Age $13=$ Solid, Age $22=$ Dashed

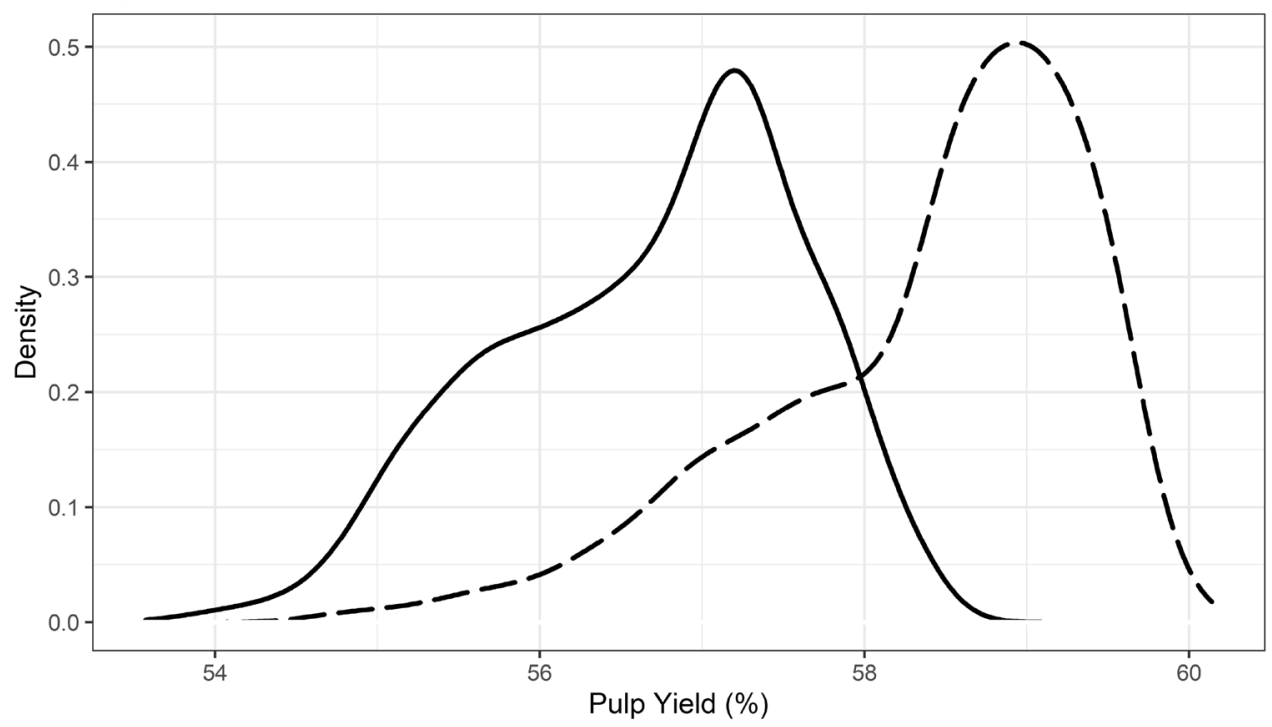

Age $13=$ Solid, Age $22=$ Dashed
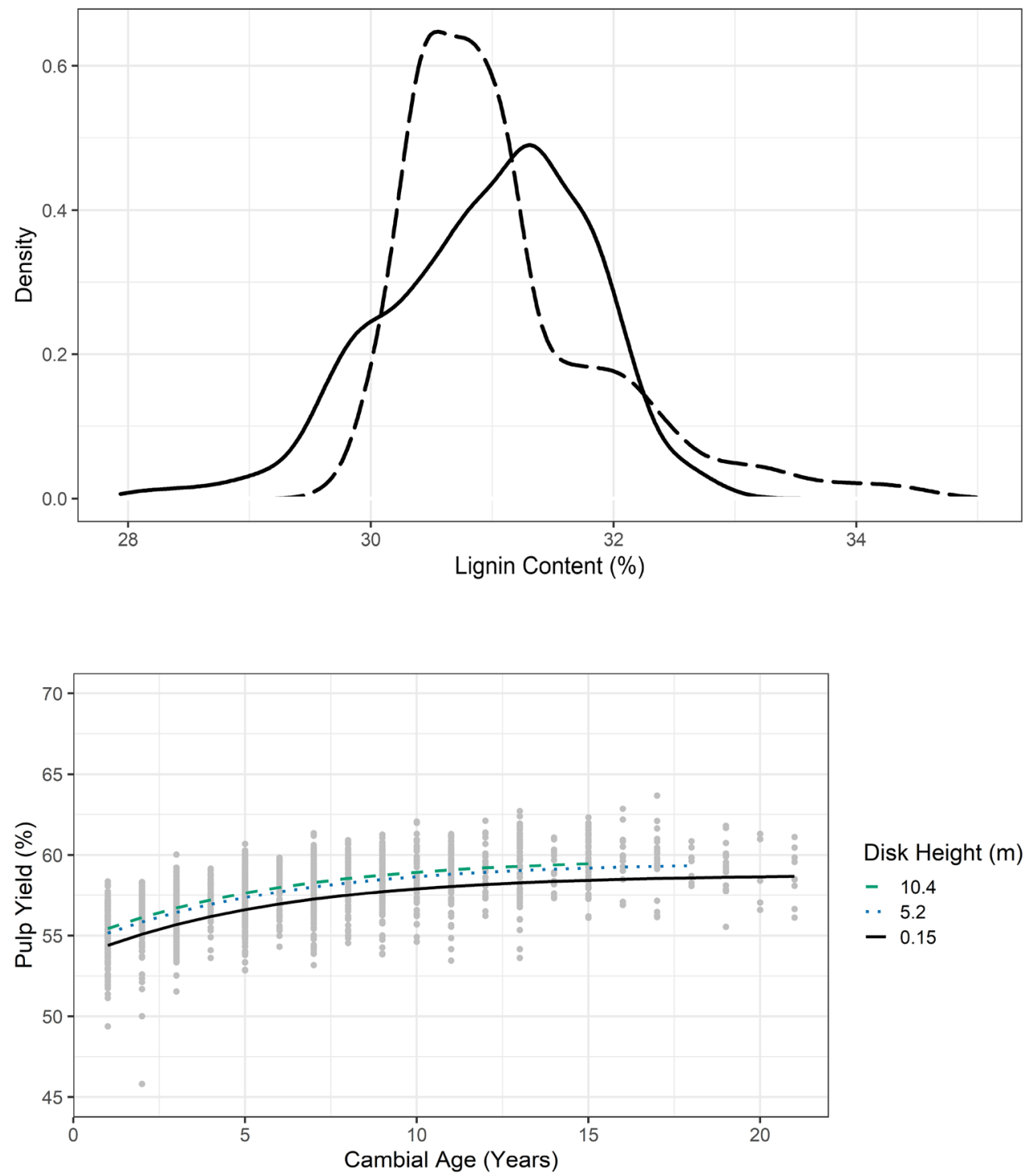

Disk Height $(\mathrm{m})$

- 10.4

. 5.2

$-0.15$ 
Fig. 6 Variation in loblolly pine lignin content by cambial age and height within tree. Lines represent the predictions from Eq. 6 at the following disk heights: $0.15 \mathrm{~m}$ (solid), $5.2 \mathrm{~m}$ (dotted), $10.4 \mathrm{~m}$ (dashed)

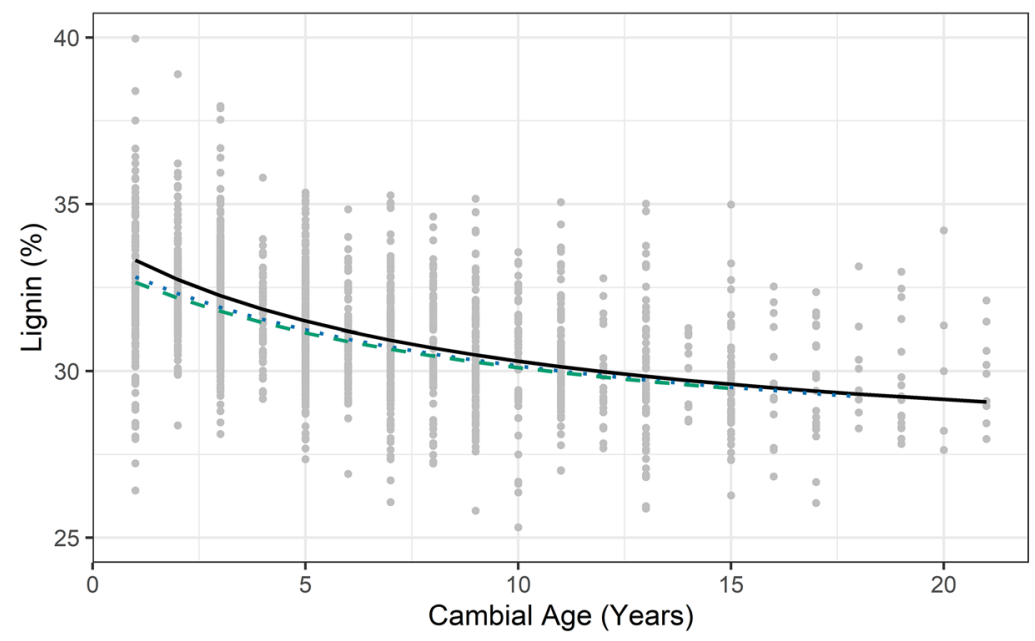

Disk Height $(\mathrm{m})$

$-0.15$

- 5.2

$-10.4$

Table 2 Parameter estimates for the pulp yield and lignin content models

\begin{tabular}{llll}
\hline Property & Parameter & Model & Disk height (Eq. 6) \\
\cline { 3 - 4 } & & Base (Eq. 5) & 58.725 \\
\hline Pulp yield (\%) & $\beta_{0}$ & 59.164 & -12.704 \\
& $\beta_{1}$ & -11.614 & 5.444 \\
& $\beta_{2}$ & 4.776 & 0.451 \\
& $\beta_{3}$ & - & Disk height (Eq. 9) \\
\hline Lignin content (\%) & & Base (Eq. 8) & 26.992 \\
& $\beta_{0}$ & 26.273 & 2.303 \\
& $\beta_{1}$ & 3.408 & 9.865 \\
& $\beta_{2}$ & - & 0.507 \\
\hline
\end{tabular}

content also varied with height, but only in the corewood. In the outerwood, the lignin content for all heights converged to a common value ( $28 \%)$. Differences in height were more subtle than pulp yield. The pulp yield model had better fit statistics than the lignin model, with the fixed effects for the final pulp yield model having an $R^{2}$ of 0.44 versus 0.20 for the lignin model (Table 3 ). In both cases, including disk height improved the model significantly ( $p$-value $<0.001$ ), although for lignin the difference was subtle. Even though the $R^{2}$ was much higher for pulp yield, the RMSE was similar (1.49\% vs. $1.68 \%$ ). The random variation by stand (age 13 and 22) was the same for both pulp yield and lignin (4\%); however, since there were only two stands, this may not reflect the variation that exists on the landscape. The random variation attributed to individual trees was similar to pulp yield (19\%) and lignin (20\%).

We utilized the spatial-interpolated approach described in Schimleck et al. [56] to generate NIR-predicted wood property data that was subsequently used to examine within-tree variation of pulp yield and lignin content in loblolly pine trees aged 13 and 22 years. This approach
Table 3 Fit indices and model errors for the pulp yield and lignin content models

\begin{tabular}{llllll}
\hline Property & Model $^{\mathrm{a}}$ & \multicolumn{2}{l}{ Fit indices $\left(R^{2}\right)$} & Model errors \\
\cline { 3 - 5 } & & Fixed & Stand & Tree & RMSE $^{\mathrm{b}}$ \\
\hline Pulp yield (\%) & Base & 0.39 & 0.45 & 0.64 & 1.55 \\
& DH & 0.44 & 0.48 & 0.67 & 1.49 \\
\multirow{2}{*}{ Lignin (\%) } & Base & 0.20 & 0.23 & 0.44 & 1.69 \\
& DH & 0.20 & 0.24 & 0.44 & 1.68 \\
\hline
\end{tabular}

${ }^{\mathrm{a} B a s e}$ model does not include disk height, $\mathrm{DH}=$ disk height model

${ }^{\mathrm{b}}$ Root mean square error (RMSE) and mean percentage error (|E\%|) are calculated from the fixed part of each model

relies on utilizing wood property data collected on wholetree composite samples and NIR spectra collected at much high resolution (10-mm increments from radial strips sampled at multiple heights) but basal area weighted to provide a single spectrum per tree. The pulp yield and lignin maps are, to the best of our knowledge, the only wholetree maps of these properties published for loblolly pine 
and the only visual representation of the change in these properties associated with maturation. The radial trends we observed for both properties are consistent with our expectations for this species based on literature reported for other pines $[5,29]$ and conifers in general $[13,40]$. In addition, our NIR-based estimates for pulp yield and lignin agree with those published by Koch [27] and McDonough et al. [36].

Ideally more samples would have been available for model development but owing to the high cost of pulp yield determination, and to a lesser degree lignin analysis, this was not possible. Having more samples may have also decreased the difference between calibration and cross-validation statistics but as each tree represents a unique addition to the model there is no guarantee that this would occur and the errors that exist may largely be a result of analytical errors in the determination of lignin and pulp yield. It is also important to recognize that the errors represented in the calibration phase that may arise owing to the unique aspects of a given individual are not critical in terms of the prediction of $10 \mathrm{~mm}$ sections, as all samples were included in the final model. Hence, variability in the prediction set was incorporated in the calibration set unlike the situation encountered during the cross-validation phase and is reported in Table 1.

Other approaches have been utilized to examine the within-tree variation of pulp yield. Specifically, Crawford et al. [7] pulped individual samples collected at various radial positions and heights in two Tasmanian grown alpine ash. This approach is the most desirable as it provides wet chemistry data for each measurement point, but owing to the time and cost involved in determining pulp yield [38], only a limited number of samples, and ultimately trees, can be sampled. Schimleck and Michell [53] utilized NIR spectroscopy and minipulping to examine pulp yield variation within 15 plantation-grown shining gum aged 18 . For these trees, individual rings (or two rings when very close together) were sampled using a drill, and the milled wood used to collect NIR spectra. Minipulping was conducted on outerwood, multi-ring samples collected at three heights from 3 trees. These data were then incorporated into an existing shining gum calibration for the region in which the trees grew. The model was used to estimate the pulp yield of individual rings, and the data were subsequently used to generate maps of pulp yield within individual trees and for an average of all trees. The approach utilized in this study allowed many more trees to be examined, and while it was observed that the variability of maps for individual trees made it impossible to determine any consistent pattern of variability, the utilization of maps based on 3 (those that provided minipulping samples) and 15 trees made conclusions regarding patterns of variability possible.
Our approach differs markedly to that of Schimleck and Michell [53], in terms of the methods used to collect spectra (milled ring samples vs spectra collected in 10- $\mathrm{mm}$ increments from radial strips), and presents a more consistent approach in terms of the collection and utilization of spectral data. As noted by [55] the time required to prepare samples is greatly reduced by avoiding the need to grind samples facilitating the analysis of more trees. With more trees (and samples) analyzed, maps based in the data are far more useful in terms of understanding wood property variation within loblolly pine, compared to data collected on a relatively small number of trees or even individual trees as with most studies of wood properties such as pulp yield and lignin.

Development of NIR systems now allows the collection of NIR data at higher spatial resolution. Recent studies have used either fiber optic probes [11,37] or NIR-HSI [32, $33,59,60$ ] with both approaches utilizing linear translation systems to collect data across samples. Both permit the investigation of within-tree variation of wood properties at the ring, or within-ring level and the production of more detailed maps [60]. The system utilized by Meder et al. [37] and Downes et al. [11] allowed wood property estimates at $1-\mathrm{mm}$ resolution; however, very precise identification of NIR measurement points was required (it was achieved in their research by integrating a NIR probe with the SilviScan system). The resolution of NIR-HSI measurements is instrument specific. For example, [59] reported a resolution of approximately $2 \mathrm{~mm}$, whereas $\mathrm{Ma}$ et al. [32] collected data at much higher resolution $(156 \mu \mathrm{m})$. Whether there is value in utilizing within-ring data for mapping the variation of wood properties within-trees (owing to the difficulties of managing very large data sets and ease of producing models at the ring level) remains to be determined. A higher-resolution system does allow for detecting narrow rings, which could be determined with the settings used by Ma et al. [32] $(156 \mu \mathrm{m})$ but not in the case of [59] (2 mm). NIR-HSI collects images and data collection is rapid; subsequently, many samples can be scanned in a day compared to the use of a fiber optic probe where spectra are collected in incremental steps. While data collection is greatly simplified, the storage and processing of data becomes more computationally intensive.

The models presented herein are the first nonlinear models developed for pulp yield and lignin content for loblolly pine to be reported in the literature. The models could be integrated into growth and yield prediction systems to estimate these properties for different scenarios (e.g., clear cut, thinning, base versus tops of trees, etc.). More research is needed to determine whether these models are applicable beyond the range of the data. The trees for this study were obtained from southwest Georgia, and likely, they do not represent the wood properties variation 
throughout the US south $[9,24]$. Due to advancements in NIR-HSI, we anticipate that within-tree models for lignin content will be developed more frequently than in the past; however, the same cannot probably be said for pulp yield as few laboratories are focused on generating this information.

The pulp yield model has a similar shape as the model for Norway spruce by Molteberg and Høibø [40] but the values are very different. These authors reported pulp yield values of $37 \%$ at the pith compared to the $55 \%$ found here; differences likely related to the target Kappa of 27-30 used by Molteberg (2004) compared to the Kappa 109 targeted here. As Kappa number decreases, chemical usage increases and therefore residual lignin content decreases which, in turn, results in lower pulp yields.

Via et al. [63] reported Klason lignin values for longleaf pine at varying heights within ten trees; these data indicate that in the corewood lignin is approximately $31 \%$, and in outerwood lignin decreases to approximately $27 \%$. The model presented here is mostly in agreement with this result for outerwood, although we found higher lignin contents near the pith (33\%). This could be due to species differences between loblolly pine and longleaf pine, differences in sites, or indicative of growth rate differences between the trees in the respective studies, among other site factors. The differences could also be due to the prediction of lignin using the spatial-interpolation approach deployed here as [63] measured lignin of specific rings.

An interesting observation is the similarity of maps reported for pulp yield and lignin to other loblolly pine wood property maps $[9,42,54,55,57]$. It is possible that separate maturation processes influence radial (corewood to outerwood) and axial (juvenile to mature) development in such a way that properties may be weakly related but still have similar internal trends. Discussion of processes is beyond the scope of this manuscript, but more information is needed from a broad sample size where the full suite of properties is measured at the same spatial scale to more clearly indicate similarities or differences between property maps.

\section{Conclusions}

The within-tree variation of pulp yield and lignin content in loblolly pine trees aged 13 and 22 years was examined utilizing wood property data obtained using the spatialinterpolated approach described in Schimleck et al. [56]. This methodology used whole-tree wood property and NIR spectral data (originally collected in $10-\mathrm{mm}$ increments at multiple radial positions and heights but basal area weighted to provide a single spectrum per tree) to successfully generate calibrations for pulp yield and lignin content. The models estimated both properties in 10-mm increments with these data used to develop maps depicting pulp yield and lignin content variation for the trees at both ages. The radial trends observed for pulp yield (increase) and lignin (decrease) were consistent with expectations for loblolly pine owing to maturation. Radial variation in properties was also modeled using mixedeffects models.

Acknowledgements Support for this work was provided by the Georgia TIP ${ }^{3}$ program and is gratefully acknowledged. The authors thank the UGA Wood Quality Consortium for collecting the loblolly pine samples and for sample preparation.

\section{Declarations}

Conflict of interest The authors declare no conflict of interest.

Open Access This article is licensed under a Creative Commons Attribution 4.0 International License, which permits use, sharing, adaptation, distribution and reproduction in any medium or format, as long as you give appropriate credit to the original author(s) and the source, provide a link to the Creative Commons licence, and indicate if changes were made. The images or other third party material in this article are included in the article's Creative Commons licence, unless indicated otherwise in a credit line to the material. If material is not included in the article's Creative Commons licence and your intended use is not permitted by statutory regulation or exceeds the permitted use, you will need to obtain permission directly from the copyright holder. To view a copy of this licence, visit http://creativecommons. org/licenses/by/4.0/.

\section{References}

1. Akima H, Gebhardt A (2016) akima: Interpolation of irregularly and regularly spaced data. $\mathrm{R}$ package version $0.6-2$, https:// CRAN.R-project.org/package $=$ akima

2. Auty D, Achim A, Macdonald E, Cameron AD, Gardiner BA (2014) Models for predicting wood density variation in Scots pine. Forestry 87:449-458

3. Batchelor BK, Crawford IA, Turner CH (1970) Assessment of a forest for pulping. Appita J 24(1):27-44

4. Batchelor BK, Prentice FJ, Turner CH (1971) Assessment of a forest for pulping 2. Appita J 24(4):253-260

5. Burdon RD, Kibblewhite RP, Walker JCF, Megraw RA, Evans R, Cown DJ (2004) Juvenile versus mature wood: A new concept, orthogonal to corewood versus outerwood, with special reference to Pinus radiata and P. taeda. For Sci 50(4):399-415

6. Çöpür Y, Makkonen H, Amidon TE (2005) The prediction of pulp yield using selected fiber properties. Holzforschung 59(5):477-480

7. Crawford IA, Prentice FJ, Turner CH (1972) Variation in pulping quality within 2 trees of $E$ delegatensis. Appita J 25(5):353-358

8. Dahlen J, Auty D, Eberhardt TL (2018) Models for predicting specific gravity and ring width for loblolly pine from intensively managed plantations, and implications for wood utilization. Forests 9:292

9. Dahlen J, Nabavi M, Auty D, Schimleck L, Eberhardt TL (2021) Models for predicting the within-tree and regional variation of 
tracheid length and width for plantation loblolly pine. Forestry 94:127-140. https://doi.org/10.1093/forestry/cpaa018

10. Defo M, Goodison A, Uy N (2009) A method to map within-tree distribution of fibre properties using SilviScan-3 data. For Chron 85(3):409-414

11. Downes GM, Meder R, Ebdon N, Bond H, Evans R, Joyce K, Southerton S (2010) Radial variation in cellulose content and Kraft pulp yield in Eucalyptus nitens using near-infrared spectral analysis of air-dry wood surfaces. J Near Infrared Spectrosc 18(2):147-155

12. Downes GM, Harwood CE, Wiedemann J, Ebdon N, Bond H, Meder R (2012) Radial variation in Kraft pulp yield and cellulose content in Eucalyptus globulus wood across three contrasting sites predicted by near infrared spectroscopy. Can J For Res 42(8):1577-1586

13. Erickson HD, Arima T (1974) Douglas-fir wood quality studies 2. Effects of age and stimulated growth on fibril angle and chemical constituents. Wood Sci Technol 8(4):255-265

14. Evans R (1994) Rapid measurement of the transverse dimensions of tracheids in radial wood sections from Pinus radiata. Holzforschung 48:168-172

15. Evans R (1999) A variance approach to the X-ray diffractometric estimation of microfibril angle in wood. Appita J 52(4):283-294

16. Evans R (2006) Wood stiffness by X-ray diffractometry. In: Stokke DD, Groom LHC (eds) Characterization of the cellulosic cell wall. Blackwell Publishing, Ames, IA, pp 138-146

17. Evans R, Downes G, Menz D, Stringer S (1995) Rapid measurement of variation in tracheid transverse dimensions in a radiata pine tree. Appita J 48(2):134-138

18. GFC (2019) 2018 Economic benefits of the forest industry in Georgia. https://gatrees.org/wp-content/uploads/2020/01/ Economic-Impact-Fact-Sheet-2018.pdf. Accessed 14 Apr 2020

19. Gierlinger N, Wimmer R (2004) Radial distribution of heartwood extractives and lignin in mature European larch. Wood Fiber Sci 36(3):387-394

20. Gray JA, Bentley JW, Cooper JA, Wall DJ (2018) Southern pulpwood production, 2016. USDA For Serv Southern Research Station, Asheville, NC, e-Resour. Bull. SRS-222 SRS-222

21. Greaves BL, Borralho NMG (1996) The influence of basic density and pulp yield on the cost of eucalypt kraft pulping: $A$ theoretical model for tree breeding. Appita J 49(2):90-95

22. Harwood VD (1971) Variation in carbohydrate analyses in relation to wood age in Pinus radiata. Holzforschung 25(3):73-77

23. Ikonen VP, Peltola $H$, Wilhelmsson L, Kilpeläinen A, Väisänen $H$, Nuutinen T, Kellomäki S (2008) Modelling the distribution of wood properties along the stems of Scots pine (Pinus sylvestris L.) and Norway spruce (Picea abies (L.) Karst.) as affected by silvicultural management. For Ecol Manag 256(6):1356-1371

24. Jordan L, Clark A, Schimleck LR, Hall DB, Daniels RF (2008) Regional variation in wood specific gravity of planted loblolly pine in the United States. Can J For Res 38(4):698-710

25. Kibblewhite RP, Evans R (2001) Dimensional relationships among radiata pine wood tracheid, and chemical and TMP pulp fibres. Appita J 54(3):297-303

26. Kim DH, Allison L, Carter B, Hou Q, Courchene C, Ragauskas AJ, Sealey J (2005) Profiling the wood and pulping properties of southern pine thinning resources. Tappi J 4(1):21-25

27. Koch P (1972) Utilization of the southern pines - Volume 2. USDA For Serv Southern Forest Experiment Station, Asheville, NC, Agricultural Handbook SFES-AH-420

28. Lachenbruch B, Moore JR, Evans R (2011) Radial variation in wood structure and function in woody plants, and hypotheses for its occurrence. In: Lachenbruch B, Dawson TE (eds) Size- and Age-Related Changes in Tree Structure and Function; Meinzer FC. Springer, Berlin, Germany, pp 121-164
29. Larson PR (1966) Changes in chemical composition of wood cells associated with age in Pinus resinosa. For Prod J 16(4):37-45

30. Larson PR, Kretschmann DE, Clark A, Isebrands JG (2001) Formation and properties of juvenile wood in southern pines: a synopsis. USDA For Serv Forest Products Laboratory, Madison, WI, Gen Tech Rep FPL-GTR-129

31. Lundqvist S-O, Ekenstedt F, Hedenberg O, Twaddle A (2005) Wood and fiber properties of loblolly pine in the southeast USA. Variations and prediction models. In: Fifth workshop, Connection Between Forest Resources and Wood Quality: Modelling Approaches and Simulation Software, Waiheke Island Resort, New Zealand, 20-27 November, 2005

32. Ma T, Inagaki T, Tsuchikawa S (2017) Calibration of SilviScan data of Cryptomeria japonica wood concerning density and microfibril angles with NIR hyperspectral imaging with high spatial resolution. Holzforschung 71(4):341-347

33. Ma T, Inagaki T, Tsuchikawa S (2018) Non-destructive evaluation of wood stiffness and fiber coarseness, derived from SilviScan data, via near infrared hyperspectral imaging. J Near Infrared Spectrosc 26(6):398-405

34. Mäkinen H, Jaakkola T, Piispanen R, Saranpää P (2007) Predicting wood and tracheid properties of Norway spruce. For Ecol Manag 241(1-3):175-188

35. Manfredi V (1985) Variations in the yield of sulphate pulp along the trunk of Eucalyptus grandis Hill ex Maiden and E. saligna Smith. MSc thesis, University of Sao Paulo, Piracicaba, Sao Paulo, Brazil.

36. McDonough TJ, Courchene CE, White DE, Schimleck L, Peter G (2012) Effects of loblolly pine tree age and wood properties on linerboard grade pulp yield and sheet properties. Part 2: Effects on sheet properties. Tappi J 11(10):41-50

37. Meder R, Marston D, Ebdon N, Evans R (2010) Spatially-resolved radial scanning of tree increment cores for near infrared prediction of microfibril angle and chemical composition. J Near Infrared Spectrosc 18(6):499-505

38. Meder R, Brawner JT, Downes GM, Ebdon N (2011) Towards the in-forest assessment of Kraft pulp yield: comparing the performance of laboratory and hand-held instruments and their value in screening breeding trials. J Near Infrared Spectrosc 19(5):421-429

39. Mevik B-H, Wehrens R, Hovde Liland K, Hiemstra P (2019) pls: Partial Least Squares and Principal Component regression. $\mathrm{R}$ package version 2.7-2. http://CRAN.R-project.org/package=pls

40. Molteberg D, Høibø O (2006) Development and variation of wood density, kraft pulp yield and fibre dimensions in young Norway spruce (Picea abies). Wood Sci Technol 40(3):173-189

41. Moore JR, Cown DJ, McKinley RB (2014) Modelling microfibril angle variation in New Zealand-grown radiata pine. $\mathrm{N} Z \mathrm{~J}$ For Sci 44:25

42. Mora CR, Schimleck LR (2009) Determination of within-tree variation of Pinus taeda wood properties by near infrared spectroscopy. Part 2: Whole-tree wood property maps. Appita J 62(3):232-238

43. Nychka D, Furrer R, Paige J, Sain S (2015) fields: Tools for spatial data. $R$ package version 8.10 , http://CRAN.R-project.org/packa ge=fields

44. Panshin AJ, de Zeeuw C (1980) Textbook of wood technology, 4th edn. McGraw-Hill, New York

45. Pereira H, Graça J, Rodrigues JC (2003) Wood chemistry in relation to quality. In: Barnett JR, Jeronimidis G (eds) Wood Quality and its Biological Basis. Blackwell Publishing Ltd, Oxford, UK, pp 53-86

46. Pinheiro J, Bates D, R Core Team (2020) nlme: Linear and nonlinear mixed effects models. R package version 3.1-147. https:// CRAN.R-project.org/package $=$ nlme. Accessed 5 May 2020 
47. Ragauskas AJ, Nagy M, Kim DH, Eckert CA, Hallett JP, Liotta CL (2006) From wood to fuels - Integrating biofuels and pulp production. Ind Biotechnol 2(1):55-65

48. Ratkowsky DA (1990) Handbook of nonlinear regression models. Marcel Dekker, New York

49. RCoreTeam (2020) R: a language and environment for statistical computing, R Foundation for Statistical Computing, Vienna, Austria. Available from http://www.R-project.org/

50. RStudio (2020) RStudio: integrated development environment for R, Boston, Mass. USA. Available from https://www.rstudio. $\mathrm{com} /$

51. Sarkar D (2008) Lattice: Multivariate data visualization with R. Springer, New York, USA

52. Scallan AM, Green HV (1975) The effect of pulping upon the dimensions of wood tracheids. Wood Fiber Sci 7:226-233

53. Schimleck LR, Michell AJ (1998) Determination of within-tree variation of kraft pulp yield using near-infrared spectroscopy. Tappi J 81(5):229-236

54. Schimleck LR, Mora CR, Jordan L, White DE, Courchene CE, Purnell RC (2009) Determination of within-tree variation of Pinus taeda wood properties by near infrared spectroscopy. Part 1: Development of multiple height calibrations. Appita J 62(2):130-136

55. Schimleck L, Antony F, Mora C, Dahlen J (2018) Comparison of whole-tree wood property maps for 13 - and 22-year-old loblolly pine. Forests 9:287

56. Schimleck LR, Antony F, Mora C, Dahlen J (2020) Comparison of whole-tree wood property maps based on near infrared spectroscopic calibrations utilizing data at different spatial resolutions. Holzforschung 74(1):20-32

57. Schimleck L, Antony F, Mora C, Dahlen J (2020) Whole-tree tracheid property maps for loblolly pine at different ages. Wood Sci Technol 54(3):683-701

58. Smook G (2016) Handbook for pulp and paper technologists, 4th edn. TAPPI Press, Peachtree Corners, Georgia

59. Thumm A, Riddell M, Nanayakkara B, Harrington J, Meder R (2010) Near infrared hyperspectral imaging applied to mapping chemical composition in wood samples. J Near Infrared Spectrosc 18(1):507-515

60. Thumm A, Riddell M, Nanayakkara B, Harrington J, Meder R (2016) Mapping within-stem variation of chemical composition by near infrared hyperspectral imaging. J Near Infrared Spectrosc 24(6):605-616

61. Tian X, Cown DJ, McConchie DL (1995) Modelling of Pinus radiata wood properties part 2: basic density. N Z J For Sci 25(2):214-230

62. Uprichard JM (1971) Cellulose and lignin content in Pinus radiata D Don within-tree variation in chemical composition, density, and tracheid length. Holzforschung 25(4):97-105

63. Via BK, So CL, Groom LH, Shupe TF, Stine M, Wikaira J (2007) Within tree variation of lignin, extractives, and microfibril angle coupled with the theoretical and near infrared modeling of microfibril angle. IAWA J. 28(2):189-209

64. White DE, Courchene $C, M c D o n o u g h ~ T$, Schimleck L, Jones $D$, Peter G, Purnell R, Goyal G (2009) Effects of specific gravity and wood chemical content on the pulp yield of loblolly pine. Tappi J. 8(4):31-36

65. Wickham H (2009) ggplot2: Elegant graphics for data analysis. Springer-Verlag, New York

66. Wickham H (2019) tidyverse. R package version 1.3.0. https:// CRAN.R-project.org/package=tidyverse. Accessed May 5, 2020

67. Williams PC, Sobering DC (1993) Comparison of commercial near infrared transmittance and reflectance instruments for analysis of whole grains and seed. J Near Infrared Spectrosc 1(1):25-32

Publisher's Note Springer Nature remains neutral with regard to jurisdictional claims in published maps and institutional affiliations. 